\title{
Folheto interpretativo como ferramenta de valorização de geossítios da Ponta de Jericoacoara, Ceará, Brasil
}

\author{
Interpretative flyer as a valorization tool in the geosites at Ponta de Jericoacoara, Ceará, \\ Brazil.
}

Meira $^{1}$, S. A.

suediomeira@gmail.com;

\section{Resumo}

A crise ambiental suscitou a valorização do patrimônio natural em escala global, porém os elementos bióticos concentram o predomínio de ações e estudos, sendo os elementos abióticos ainda pouco estudados. Diante disso, o presente artigo aborda a relevância científica e turística do patrimônio geológico da Ponta de Jericoacoara (Ceará, Brasil), por meio da proposta de um folheto interpretativo-turístico. A metodologia parte da busca de referencial teórico, seguido da realização de trabalhos de campo para a inventariação do patrimônio geológico. Por fim, foi confeccionado um folheto interpretativo dos geossítios da Ponta de Jericoacoara por meio de softwares de edição de imagem e design gráfico. O folheto revela a importância da interpretação ambiental em práticas de valorização do patrimônio geológico e a necessidade de apropriação da atividade turística para a educação ambiental, visando a difusão de conhecimento científico referente às Ciências da Terra.

Palavras-chave: Patrimônio Geológico. Geocomunicação. Geoconservação.

\begin{abstract}
The environmental crisis raised the natural heritage valorization in a global scale, however the biotic elements attract most efforts, research and actions, being the abiotic elements less studied. In face of that reality, the present paper approaches the scientific and touristic relevance of the Ponta de Jericoacoara (Ceará, Brazil) geoheritage, by proposing a touristic-interpretative flyer. The methodology begins by a bibliography review, followed by field research to make the geoheritage inventory. Finally, we elaborated an interpretative flyer about the Ponta de Jericoacoara geosites using graphical design and photos. The flyer shows the importance of the environmental interpretation in geoheritage valorization practices and the necessity of touristic activity appropriation for environmental education, aiming the diffusion of scientific knowledge related to Earth Sciences
\end{abstract}

Keywords: Geoheritage. Geocommunication. Geoconservation.

\section{INTRODUÇÃO}

Comunicação é uma palavra derivada do termo latino "communicare" que significa, a grosso modo, partilhar, participar algo, tornar comum. É papel das ciências comunicarem no meio acadêmico os conhecimentos adquiridos e formulados no intuito de fortalecerem suas bases conceituais e teóricas, porém, é certo afirmar que cada vez mais também é papel das ciências transcenderem a academia e difundirem as descobertas para o público geral, compartilhar o conhecimento de forma acessível, sendo esse fato especialmente necessário em meio às ciências ambientais mediante a problemática ambiental que tem se instaurado nas ultimas décadas.

Um dos grandes problemas enfrentados pelas Ciências da Terra para a difusão de seus conhecimentos é devido sua linguagem extremamente técnica. Tal linguagem não permite, em muitos momentos, uma comunicação satisfatória. O conhecimento fica restrito a um nicho restrito de pesquisadores perdendo sua potencialidade diante a instituição de medidas de valorização

${ }^{I}$ Suedio Alves Meira, Doutorando em Geografia, Laboratório de Geoecologia da Paisagem e Planejamento Ambiental, Universidade 
ambiental. É correto afirmar que há momentos em que a comunidade não preserva a geodiversidade por não compreender a relevância que os elementos abióticos da paisagem adquirem no complexo sistema que é a natureza. Diante essa problemática um dos desafios das Ciências da Terra é o desenvolvimento de uma "Geocomunicação", ou seja, a elaboração de uma linguagem e/ou conjunto de ações práticas ligadas à interpretação ambiental que permita partilhar, tornar público, tornar comum o conhecimento geológico.

Em meio a essa problemática passam a ser desenvolvidos, a partir da década de 1990, estudos entorno das temáticas da Geodiversidade, Patrimônio Geológico e Geoconservação. Borba (2011) expõe o caráter ambientalista que os estudos em geodiversidade apresentam devido ao período histórico de sua formulação, durante a Conferência da Organização das Nações Unidas para o Meio Ambiente e Desenvolvimento, realizada na cidade do Rio de Janeiro em 1992, e o fato do conceito funcionar como um contraponto ao de biodiversidade.

Enquanto a geodiversidade se configura como a totalidade dos elementos abióticos presentes na paisagem o Patrimônio Geológico é definido de acordo Carcavilla et al (2008, p. 3001, tradução nossa) como "o conjunto de elementos geológicos que se destacam por seu valor científico, cultural ou educativo", ou seja, são aquelas feições que apresentam relevância de acordo a percepção humana, sendo assim necessária a sua manutenção para a posteridade. O conjunto de ações que visam à conservação e a gestão do patrimônio geológico e definido como Geoconservação.

Lima (2008) descreve as etapas necessárias numa estratégia de geoconservação, sendo elas a inventariação, avaliação quantitativa, conservação, valorização, divulgação e monitoramento do patrimônio geológico. As etapas de valorização e divulgação do patrimônio geológico compreendem a tradução do conhecimento científico numa linguagem acessível, sendo nesse momento em que se transcendem os "muros" da academia e se busca a difusão das informações obtidas para o maior número de pessoas possível.

Diante o exposto o presente trabalho tem objetivo propor uma estratégia de valorização e divulgação do patrimônio geológico presente na Ponta de Jericoacoara, a qual está inserida no âmbito do Parque Nacional de Jericoacoara (PNJ), município de Jijoca de Jericoacoara no litoral oeste do estado do Ceará. A estratégia adotada foi a confecção de um folheto interpretativo-turístico propondo uma trilha que perpassa por diferentes geossítios presentes na área de estudo, os quais apresentam relevante potencialidades científicas, educativas e turísticas.

A escolha da área deu-se devido à diversidade de ambientes e feições geológicas e pela visibilidade midiática que a mesma apresenta devido ao intenso fluxo turístico presente, sendo um dos intuitos do trabalho se apropriar de práticas comuns à atividade turística para a divulgação de conhecimento científico por meio de ações de educação ambiental. 


\section{METODOLOGIA}

A metodologia utilizada parte do levantamento bibliográfico sobre conceitos relativos às temáticas da Geodiversidade, Patrimônio Geológico, Geoconservação, Interpretação Ambiental e sobre o ambiente físico do Parque Nacional de Jericoacoara (PNJ).

Um segundo momento foi caraterizada por trabalhos de campo para o inventário dos geossítios da Ponta de Jericoacoara. Como auxílio na etapa de inventariação foi confeccionada uma ficha de caracterização dos locais de interesse geológico, sendo esta uma adaptação da proposta por Pereira (2006). A escolha dos locais partiu da representatividade no contexto da geodiversidade local, potencialidade científica, potencialidade didática e o apelo estético das feições.

Por fim, foi confeccionado um folheto turístico-interpretativo sobre os geossítios da Ponta de Jericoacoara. O tratamento das imagens presentes no folheto deu-se por meio do software de edição de imagem Adobe Lightroom 5.6, onde foram corrigidos aspectos referentes à exposição, contraste, balanço de pretos, brancos, sombras e realce. Para a confecção do desenho (layout) do folheto foi utilizado o software de design gráfico Adobe Illustrator CS6.

\section{RESULTADOS E DISCUSSÃO}

\subsection{Características dos Geossítios da Ponta de Jericoacoara}

A Ponta de Jericoacoara é um sítio geomorfológico catalogado e descrito pela Comissão Brasileira de Sítios Geológicos e Paleobiológicos (SIGEP) (JULIO et al, 2013), sendo sua relevância justificada pela presença de afloramentos rochosos neoproterozóicos, pouco comum no litoral nordestino, e por feições geomorfológicas quaternárias que remontam a evolução geológica do promontório, marcada por variação do nível do mar.

Diferente da pesquisa concretizada por Julio et al (2013) que realiza uma descrição pormenorizada dos elementos da geodiversidade presente em toda a área, pretende-se nesse trabalho elencar pontos de maior relevância científica e turística (geossítios) passíveis de apropriação em práticas educativas. Diante disso foram elencados cinco geossítios na Ponta de Jericoacoara, sendo quatro de caráter pontual (Duna do Pôr do Sol, Cavernas, Pedra Furada e Pedra do Frade) e um geossítio de caráter área (Praia da Malhada).

O geossítio Duna do Pôr do Sol é uma duna móvel do tipo barcana que apresenta migração de leste para oeste. Meireles (2011) expõe que a formação do campo de dunas de Jericoacoara deu-se em períodos de nível de mar mais rebaixado que o atual, onde se tinha uma maior zona de estirâncio 
que permitia o retrabalhamento dos sedimentos pela ação eólica, já que a dinâmica sedimentar atual não tem capacidade de originar dunas das dimensões encontradas na área.

O geossítio Praia da Malhada apresenta grande diversidade abiótica, porém, o contato entre rochas quartzíticas neoproterozóicas (Toniano) da Formação São Joaquim com arenitos de praia de idade holocênicas é a sua principal característica (MEIRELES e RAVENTOS, 2002; JULIO, 2012). A fácil identificação do contato faz com que o local seja passível de utilização em explanações sobre diferentes formações e tipos de rochas, agregando elevado valor científico e didático ao local.

O geossítio Cavernas é composto pelo afloramento de rochas da Formação São Joaquim (área do Serrote) na linha de costa, formando uma escarpa rochosa. Nesse local se desenvolvem, fruto do trabalho marinho, feições erosivas no formato de pequenas cavernas. As cavernas estão a até seis metros acima do nível do mar atual (MEIRELES e RAVENTOS, 2002; JULIO, 2012) e sua gênese se deu em períodos de nível do mar elevado a 120.000 A.P. (JULIO et al, 2013).

O geossítio Pedra Furada é um arco marinho composto por quartzitos fraturados da Formação São Joaquim e fruto de processos erosivos marinhos. A erosão marinha resulta em rochas bem polidas e com cantos arredondados, Julio (2012, p. 59) salienta que "esse processo tem sido incrementado pelos sais presentes na água marinha e no vapor d'água que entra nas fraturas e poros da rocha. Ao cristalizarem-se os sais formam a desintegração rochosa”.

Os pilares marinhos são porções mais resistentes de rocha que permanecem como testemunho mesmo após a ação erosiva das ondas, sendo o geossítio Pedra do Frade o melhor exemplar encontrado na Ponta de Jericoacoara.

\subsection{Folheto interpretativo-turístico dos Geossítios da Ponta de Jericoacoara}

O objetivo principal do folheto interpretativo/turístico é informar ao visitante a existência e a importância do patrimônio geológico da Ponta de Jericoacoara e como esses locais remontam a história evolutiva da região no intuito de fortalecer ações de conservação e a consolidação de uma consciência ambiental (Quadro 1). A proximidade entre os geossítios e a possibilidade da realização de uma trilha a pé, com aproximadamente $4,2 \mathrm{~km}$ de extensão total, constitui elemento fundamental na escolha da estratégia de valorização (Figura 1).

O folheto interpretativo foi a técnica escolhida por ser "instrumento interpretativo para visitantes que não tem tempo ou não optarem pela compra de outros meios (como o guia de bolso, por exemplo), e que mesmo assim desejam levar informações” (MOREIRA, 2012, p. 93), por ser uma estratégia de baixo custo, fácil aplicação, sendo um material de divulgação da Unidade de Conservação, por conter mais informações do que painéis interpretativos (MOREIRA, 2012), baixo 
risco de vandalismo, não interfere com o valor estético dos geossítios (VASQUEZ, 2010) e pode ser transportado pelo visitante e ajudando-os na organização da visita (PACHECO e BRILHA, 2014).

\begin{tabular}{|c|c|c|c|c|c|}
\hline Geossítios & $\begin{array}{l}\text { Duna do Pôr } \\
\text { do Sol }\end{array}$ & $\begin{array}{l}\text { Praia da } \\
\text { Malhada }\end{array}$ & Cavernas & Pedra Furada & Pedra do Frade \\
\hline $\begin{array}{l}\text { O que } \\
\text { interpretar? } \\
\text { (Escolha do tema } \\
\text { principal) }\end{array}$ & $\begin{array}{l}\text { Principais } \\
\text { agentes e } \\
\text { processos na } \\
\text { formação da } \\
\text { duna. }\end{array}$ & $\begin{array}{l}\text { O contato entre } \\
\text { diferentes } \\
\text { formações } \\
\text { geológicas. }\end{array}$ & $\begin{array}{l}\text { Processo erosivo } \\
\text { ocasionado por } \\
\text { variações do } \\
\text { nível do mar. }\end{array}$ & $\begin{array}{l}\text { Processo erosivo } \\
\text { devido ação } \\
\text { marinha. } \\
\text { Prolongamento da } \\
\text { anterior. }\end{array}$ & $\begin{array}{l}\text { Características } \\
\text { intrínsecas da rocha } \\
\text { (falhas, fraturas, } \\
\text { inclinação, etc.) }\end{array}$ \\
\hline $\begin{array}{l}\text { Por que? } \\
\text { (Objetivos) } \\
1 \text { - O que se } \\
\text { pretende que eles } \\
\text { conheçam? }\end{array}$ & $\begin{array}{l}\text { Que o vento é } \\
\text { um dos } \\
\text { principais agente } \\
\text { na formação do } \\
\text { campo de dunas. } \\
\text { Processos atuais. }\end{array}$ & $\begin{array}{c}\text { Que os dois } \\
\text { principais tipos } \\
\text { de rocha } \\
\text { apresentam } \\
\text { idades e proces- } \\
\text { sos de formação } \\
\text { diferenciados. }\end{array}$ & $\begin{array}{c}\text { Que o mar já } \\
\text { teve diferentes } \\
\text { níveis durante o } \\
\text { pleistoceno e que } \\
\text { isso influenciou } \\
\text { no processo } \\
\text { erosivo. }\end{array}$ & $\begin{array}{l}\text { Que a ação marinha } \\
\text { é o principal agente } \\
\text { erosivo sobre as } \\
\text { rochas. Comple- } \\
\text { mentar a discussão } \\
\text { sobre os diferentes } \\
\text { níveis do mar. }\end{array}$ & $\begin{array}{l}\text { Que as rochas } \\
\text { metamórficas da } \\
\text { Formação São } \\
\text { Joaquim apresentam } \\
\text { falhas e fraturas o } \\
\text { que permite maior } \\
\text { processo erosivo. }\end{array}$ \\
\hline $\begin{array}{r}2-\mathrm{O} \text { qu } \\
\text { pretende qu } \\
\text { sintam }\end{array}$ & \multicolumn{5}{|c|}{$\begin{array}{l}\text { - Curiosidade em relação aos aspectos abióticos do Parque Nacional de Jericoacoara, suas características } \\
\text { e processos de evolução. - Concebam que as rochas e o relevo são elementos importantes no contexto } \\
\text { ambiental e que, apesar de parecer o contrário, são multáveis e necessitam de proteção.- Vontade de } \\
\text { conservar os elementos da geodiversidade. }\end{array}$} \\
\hline $\begin{array}{c}\text { Quem? } \\
\text { (Público alv }\end{array}$ & \multicolumn{5}{|c|}{$\begin{array}{l}\text { - O público alvo é caracterizado pelo turista tradicional que visita o Parque Nacional de Jericoacoara. A } \\
\text { maioria em busca de Turismo de Sol e Praia de forma que as informações devem ser passadas de forma } \\
\text { didática e interessante, já que o turismo didático/científico não é o intuito inicial do passeio. Devido a } \\
\text { características da trilha (com trechos com certa dificuldade para crianças) o texto será voltado para o } \\
\text { público adolescente e adulto (a partir dos } 13 \text { anos). }\end{array}$} \\
\hline
\end{tabular}

Quadro 1: Plano interpretativo dos Geossítios da Ponta de Jericoacoara. Fonte: Meira, 2016, p. 108.

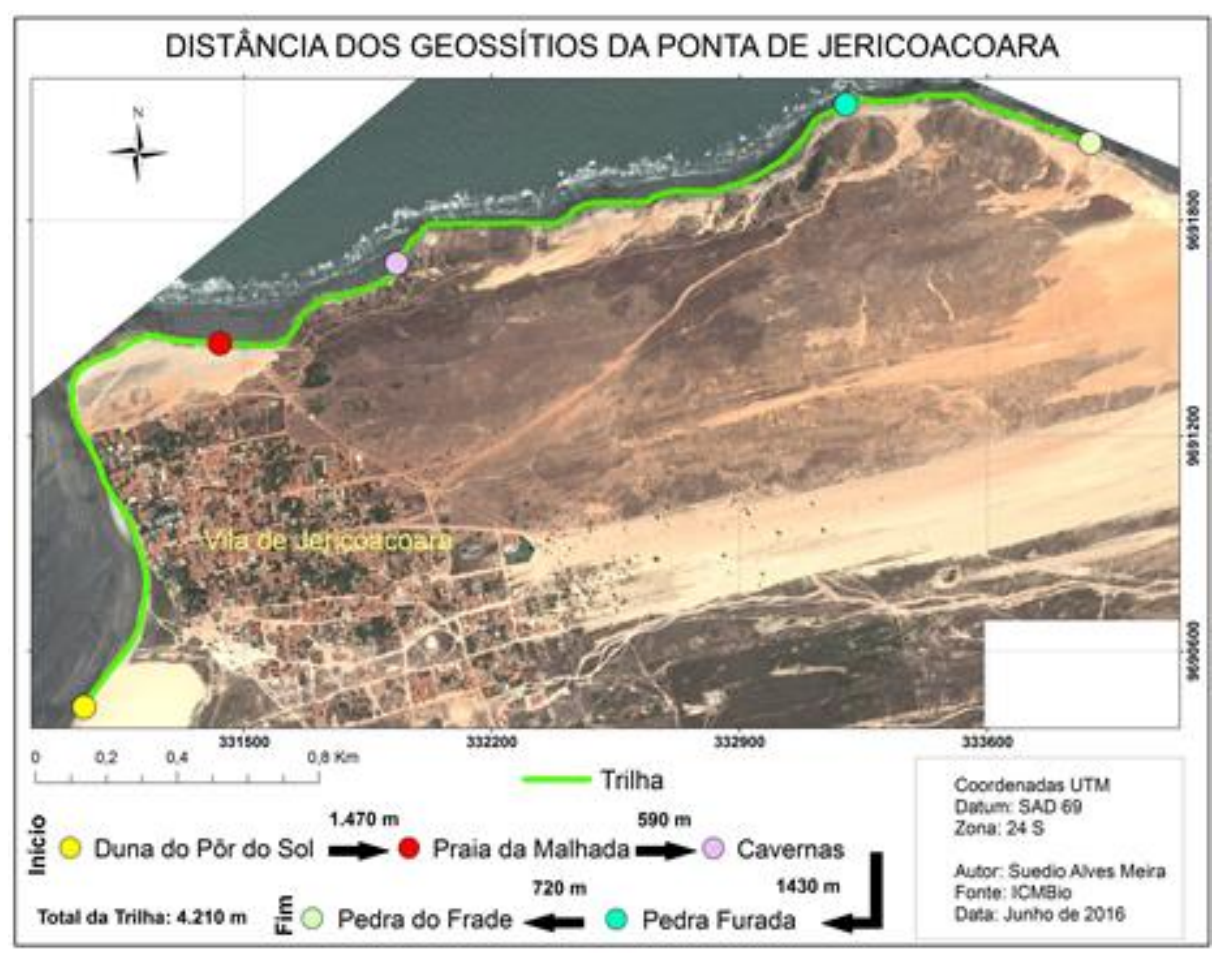

Figura 1: Localização e distância entre os geossítios da Ponta de Jericoacoara. Fonte: Elaborado pelo autor.

O texto presente no folheto (Figura 2) foi corrigido por uma profissional da área de Comunicação Social (Publicidade e Propaganda), sendo essa ação de suma importância, já que com os apontamentos resultaram em um texto com leitura mais dinâmica e atrativa ao público. Para o 
folheto interpretativo cumprir o seu papel informativo é necessário que o mesmo seja claro na abordagem dos temas, mediante o fato do turista não ter como tirar dúvidas que venham a surgir durante sua utilização. O auxílio do profissional externo permitiu essa clareza e reafirmou o caráter interdisciplinar das temáticas do Patrimônio Geológico e Geoconservação.
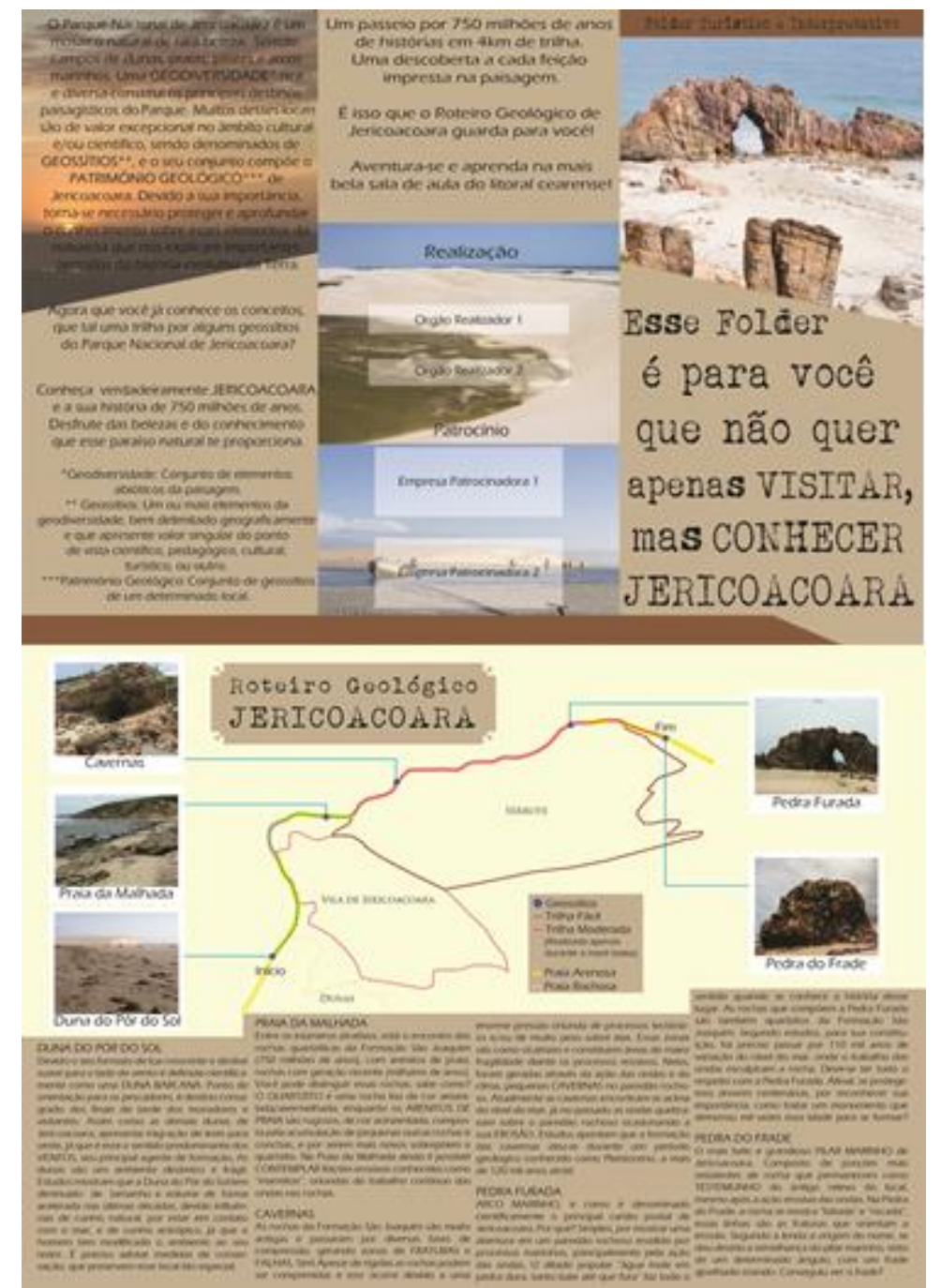

Figura 2: Folheto interpretativo-turístico da Ponta de Jericoacoara (Externo e Interno). Fonte: Meira, 2016, p. 157-158.

O percurso proposto tem como ponto de partida o geossítio Duna do Pôr do Sol. No único geossítio de caráter eólico elencado para o roteiro da Ponta de Jericoacoara foi abordado o vento como principal agente de formação, a tipologia da duna e o caráter dinâmico e frágil de ambientes eólicos, o que faz necessário alçar medidas de conservação, já que a ação antrópica já tem influenciado na sua dinâmica (Quadro 2).

O segundo geossítio do folheto é a Praia da Malhada aproximadamente 1.470 metros da Duna do Pôr do Sol. O roteiro propõe uma caminhada pela zona de costa, passando assim pela principal praia da Vila de Jericoacoara. O geossítio Praia da Malhada é de caráter área e se estende desde a curva do promontório da Ponta de Jericoacoara até o início da escarpa rochosa do Serrote, são 
aproximadamente 600 metros de extensão, porém os elementos abordados no folheto são melhor visualizados no ponto médio da praia. A Praia da Malhada é o geossítio que apresenta a maior geodiversidade passível de abordagem, porém foram selecionados dois principais: 1- O contato das distintas litologias, dando ênfase à diferença de idade das mesmas. Sendo o turista incentivado no texto a distinguir as rochas (Quadro 2). 2- As feições erosivas oriundas do trabalho das ondas (marmitas).

\section{Duna do Pôr do Sol}

Devido o seu formato de lua crescente e declive suave para o lado do vento é definida cientificamente como uma DUNA BARCANA. Ponto de orientação para os pescadores é destino consagrado dos finais de tarde dos moradores e visitantes. Assim como as demais dunas de Jericoacoara, apresenta migração de leste para oeste, já que é esse o sentido predominante dos VENTOS, seu principal agente de formação. As dunas são um ambiente dinâmico e frágil. Estudos mostram que a Duna do Pôr do Sol tem diminuído de tamanho e volume de forma acelerada nas últimas décadas, devido influências de cunho natural, por estar em contato com o mar, e de cunho antrópico, já que o homem tem modificado o ambiente ao seu redor. É preciso adotar medidas de conservação, que preservem esse local tão especial.

\section{Praia da Malhada}

Entre os inúmeros atrativos, está o encontro das rochas quartzíticas da Formação São Joaquim (750 milhões de anos), com arenitos de praia, rochas com geração recente (milhares de anos). Você pode distinguir essas rochas, sabe como? O QUARTZITO é uma rocha lisa de cor amarelada/avermelhada, enquanto os ARENITOS DE PRAIA são rugosos, de cor acinzentada, composta pela acumulação de pequenas outras rochas e conchas, e por serem mais novos sobrepõem o quartzito. Na Praia da Malhada ainda é possível CONTEMPLAR feições erosivas conhecidas como "marmitas", oriundas do trabalho continuo das ondas nas rochas.

Quadro 2: Caracterização dos Geossítios Duna do Pôr do Sol e Praia da Malhada. Fonte: Adaptado de Meira, 2016.

O geossítio Cavernas é a terceira parada proposta. As cavernas estão distribuídas em três pontos da escarpa rochosa a nordeste do Serrote. É possível chegar nelas pela zona de praias durante o período da maré baixa e o caminho é de aproximadamente 2.060 metros do inicio da trilha. Dos geossítios esse é o que apresenta o conteúdo mais complexo, mas tentou-se tratar de assuntos como a deformação de rochas metamórfica por processos de tectonismo, fraturas e falhas, erosão marinha e variações do nível do mar da forma mais simples possível e alçando de comparações (Quadro 3).

A Pedra Furada é o quarto geossítio abordado. Diferente dos percursos convencionais propostos pelas agências de turismo a chegada a Pedra Furada não é realizada pelo Serrote, mas sim pela zona de praia, estando 3.490 metros do ponto de partida (Figura 2). O caminho proposto entre o geossítio Praia da Malhada e o geossítio Pedra Furada, passando pelo geossítio Cavernas, só pode ser realizado durante a maré baixa e é repleto de pilares marinhos e piscinas naturais com elevado apelo cênico. No geossítio da Pedra Furada foi abordado sobre a ação marinha (em especial das ondas) como principal agente erosivo na instituição do arco marinho (Quadro 3). São tratados temas semelhantes ao do geossítio Cavernas o que vem fortalecer o aprendizado sobre processos erosivos.

O fim do percurso é compreendido pelo geossítio Pedra do Frade, o qual está localizado a aproximadamente 720 metros da Pedra Furada. É abordado o fato de a feição ser o maior exemplar de pilar marinho da Ponta de Jericoacoara, sendo assim um testemunho do processo erosivo (Quadro 3). As fraturas e falhas das rochas da Formação São Joaquim também é salientado no texto, 
o autor remeteu a temática ao texto anteriormente discutido e o uso de comparações com elementos do cotidiano também foi utilizado para uma melhor abordagem (Quadro 3).

\begin{tabular}{|l|}
\hline Cavernas \\
\hline As rochas da Formação São Joaquim são muito antigas e passaram por diversas fases de compressão, gerando zonas de \\
FRATURAS e FALHAS. Sim! Apesar de rígidas as rochas podem ser comprimidas e isso ocorre devido a uma enorme \\
pressão oriunda de processos tectônicos e/ou de muito peso sobre elas. Essas zonas são como cicatrizes e constituem áreas \\
de maior fragilidade diante os processos erosivos. Nelas, foram geradas através da ação das ondas e do clima, pequenas \\
CAVERNAS no paredão rochoso. Atualmente as cavernas encontram-se acima do nível do mar, já no passado as ondas \\
quebravam sobre o paredão rochoso ocasionando a sua EROSÃO. Estudos apontam que a formação das cavernas deu-se \\
durante um período geológico conhecido como Pleistoceno, a mais de 120 mil anos atrás!
\end{tabular}

\section{Pedra Furada}

ARCO MARINHO é como é denominado cientificamente o principal cartão postal de Jericoacoara. Por quê? Simples, por mostrar uma abertura em um paredão rochoso erodido por processos marinhos, principalmente pela ação das ondas. O ditado popular "água mole em pedra dura, tanto bate até que fura" faz todo o sentido quando se conhece a história desse lugar. As rochas que compõem a Pedra Furada são também quartzitos da Formação São Joaquim. Segundo estudos, para sua constituição, foi preciso passar por 110 mil anos de variação do nível do mar, onde o trabalho das ondas esculpiram a rocha. Deve-se ter todo o respeito com a Pedra Furada. Afinal, se protegemos árvores centenárias, por reconhecer sua importância, como tratar um monumento que demorou mil vezes essa idade para se formar?

\section{Pedra do Frade}

O mais belo e grandioso PILAR MARINHO de Jericoacoara. Composto de porções mais resistentes de rocha que permanecem como TESTEMUNHO do antigo relevo do local, mesmo após a ação erosiva das ondas. Na Pedra do Frade, a rocha se mostra "fatiada" e "riscada", essas linhas são as fraturas que orientam a erosão. Segundo a lenda a origem do nome, se deu devido a semelhança do pilar marinho, visto de um determinado ângulo, com um frade ajoelhado orando. Conseguiu ver o frade?

Quadro 3: Caracterização dos Geossítios Cavernas, Pedra Furada e Pedra do Frade. Fonte: Adaptado de Meira, 2016.

O folheto foi confeccionado para o tamanho de folha A4 (210mm por $297 \mathrm{~mm})$, sendo dobrado em três, o que gerou seis partes (Figura 2). A frente apresenta o título do folheto "Esse Folder é para você que não quer apenas VISITAR, mas CONHECER JERICOACOARA”, a frase foi composta para gerar impacto e palavras chaves aparecem em maiúsculo para reafirmar o objetivo do folheto que é auxiliar o turista a conhecer verdadeiramente o PNJ (Figura 2).

A página após a capa apresenta um texto explicativo sucinto sobre os aspectos da geodiversidade do PNJ, sendo nesse momento que são apresentados os conceitos de Geodiversidade, Geossítio e Patrimônio Geológico (Quadro 4). A abordagem dos conceitos foi realizada de forma simples e acompanhada de sua explicação no fim da página. Nesse momento que também é exposto o objetivo do folheto turístico (uma trilha por alguns dos geossítios presentes no PNJ).

\section{Texto da Segunda Página}

O Parque Nacional de Jericoacoara é um mosaico natural de rara beleza. Serrote, campos de dunas, praias, pilares e arcos marinhos. Uma GEODIVERSIDADE* rica e diversa constitui os principais destinos paisagísticos do Parque. Muitos desses locais são de valor excepcional no âmbito cultural e/ou cientifico, sendo denominados de GEOSSÍTIOS**, e o seu conjunto compõe o PATRIMÔNIO GEOLÓGICO*** de Jericoacoara. Devido a sua importância, torna-se necessário proteger e aprofundar o conhecimento sobre esses elementos da natureza que nos explicam importantes períodos da história evolutiva da Terra.

Agora que você já conhece os conceitos, que tal uma trilha por alguns geossítios do Parque Nacional de Jericoacoara?

Conheça verdadeiramente JERICOACOARA e a sua história de 750 milhões de anos. Desfrute das belezas e do conhecimento que esse paraíso natural te proporciona.

*Geodiversidade: Conjunto de elementos abióticos da paisagem.

** Geossítios: Um ou mais elementos da geodiversidade, bem delimitado geograficamente e que apresente valor singular do ponto de vista científico, pedagógico, cultural, turístico, ou outro.

***Patrimônio Geológico: Conjunto de geossítios de um determinado local. 
Quadro 4:Texto explicativo do Folheto Turístico/Interpretativo. Fonte: Adaptado de Meira, 2016.

A parte interna do folheto é composta pela representação da trilha proposta e os textos interpretativos de cada geossítio (Quadros 2 e 3). É utilizado um mapa turístico sem informação de coordenadas geográficas e escala gráfica, mas com legenda dos elementos ilustrativos para delinear a trilha (Figura 2). O fundo do folheto conta com texto, informação relativa à distância total da trilha, sendo separado um espaço para logotipos das instituições realizadoras e nome de patrocinadores, no intuito de que o folheto sirva com modelo para aplicação e circulação futura.

\section{CONSIDERAÇÕES FINAIS}

As temáticas da Geodiversidade, Patrimônio Geológico e Geoconservação configuram-se como importantes campos de estudo em meio as Ciências da Terra mediante o caráter ambientalista que apresentam e a preocupação em difundir conceitos e temas dessa área do conhecimento, a qual é subentendida por grande parcela da população devido a complexidade inerente, mas é de suma importância para a instituição de medidas de preservação ambiental completas.

Medidas de interpretação ambiental como a promoção do folheto interpretativo-turístico da Ponta de Jericoacoara, realizado no presente trabalho, devem ser incentivadas tanto no âmbito acadêmico, por meio de pesquisas científicas no campo da Geologia, Geografia, Turismo, Ciências Ambientais, entre outros, bem como no âmbito prático, através da adoção de ações semelhantes por órgãos de gestão ambiental. A geocomunicação, enquanto instrumento da interpretação ambiental, ergue-se como uma ferramenta que traduz o conhecimento geológico para linguagem entendível a grande parcela da população e auxilia no desenvolvimento dos trabalhos.

Ao confeccionar o folheto interpretativo-turístico utilizou-se uma linguagem acessível através da apropriação de elementos do cotidiano, buscando a consolidação de uma experiência significativa e que provocasse no turista o interesse em buscar mais conhecimento sobre a paisagem, que o mesmo não apenas a contemplasse, mas que a entendesse como sugere o título.

$\mathrm{O}$ folheto interpretativo-turístico se apropriou de uma prática turística estéril (turismo contemplativo de sol e praia) para a inserção de conhecimento científico com o intuito de contribuir na formação de uma consciência ambiental por parte do visitante. Salientasse então que estudos como esses, que apresentam simplicidade em suas ações, devem ser incentivados em todo o país, mediante a potencialidade ambiental que o Brasil detém.

\section{REFERÊNCIAS}

BORBA, A. W.. Geodiversidade e geopatrimônio como bases para estratégias de geoconservação: conceitos, abordagens, métodos de avaliação e aplicabilidade no contexto do Estado do Rio Grande do Sul. Pesquisas em Geociências, n. 38, v. 1. Porto Alegre: 2011. 
CARCAVILLA, L.; DURÁN, J. J.; LOPEZ-MARTÍNES, J.. Geodiversidade: concepto y relación com el patrimônio geológico. Geo-Temas, v. 10. Las Palmas de Gran Canaria: 2008.

JULIO, K.. A Ponta de Jericoacoara e seu potencial como sítio geológico no Brasil no patrimônio Mundial (World Heritage Comitte - UNESCO). Dissertação de mestrado apresentado ao Programa de Pós Graduação em Ciências Marinhas Tropicais da Universidade Federal do Ceará, Fortaleza, 2012.

JUliO, K; MAGINI, C.; MAIA, L. P.; CASTRO, J. W. A. Ponta de Jericoacoara, CE: Belo promontório de rochas neoproterozóicas associadas a praias e dunas quaternárias com registros de variações do nível do mar. In Sítios geológicos e Paleontológicos do Brasil. v. 3. Brasília: CPRM, 2013, 332p.

LIMA, F. F. de. Proposta metodológica para a inventariação do patrimônio geológico brasileiro. Dissertação apresentada ao Mestrado em Património Geológico e Geoconservação da Universidade do Minho, Braga. 2008.

MEIRA, S. A.. Pedras que Cantam: O patrimônio geológico do Parque Nacional de Jericoacoara, Ceará, Brasil. Dissertação de mestrado apresenta ao Programa de Pós Graduação em Geografia da Universidade Estadual do Ceará, Fortaleza, 2016. 169 p.

MEIRELES, A. J. A; RAVENTOS, J. S.. Um modelo geomorfológico integrado para a planície costeira de Jericoacoara/Ceará. Mercator, n. 1. Fortaleza: 2002.

MEIRELES, A. J. A.. Geodinâmica dos campos de Dunas Móveis de Jericoacoara. Mercator, v. 10, n. 22. Fortaleza: 2011.

MOREIRA, J. C.. Interpretação ambiental, aspectos geológicos e geomorfológicos. Boletim de Geografia, v. 30, n.2. Maringá: 2012.

PACHECO, J; BRILHA, J. Importância da interpretação na divulgação do património geológico: uma revisão. Comunicações Geológicas, v. 101, n. 1. Portugal: 2014.

PEREIRA, P.. Património geomorfológico: conceptualização, avaliação e divulgação: Aplicação ao Parque Natural de Montesinho. Tese de doutorado apresentada a Escola de Ciências da Universidade do Minho, Braga. 2006.

VASQUEZ, L. M. J.. Estratégia de Valorização de Geossítios no Geopark Arouca. Dissertação apresentada ao Mestrado em Património Geológico e Geoconservação da Universidade do Minho, Braga. 2010.

Recebido em: 14/08/2016

Aceito para publicação em: 01/10/2016 
Meira, REGNE, Vol. 2, $N^{\circ}$ Especial (2016) 